\title{
A regulamentação da fase de planeamento da contratação pública: reflexões sobre o regime legal e as orientações do direito europeu
}

JORGE FARIA LOPES ${ }^{1}$

\section{RESUMO}

Neste artigo, procura-se delimitar a relevância jurídica que a fase de planeamento possui para a prossecução dos objetivos do direito europeu da contratação pública e, a essa luz, analisar as normas constantes das Diretivas de contratação pública que se dirigem expressamente à fase de planeamento, em particular o regime dos anúncios de pré-informação e das consultas preliminares ao mercado. Nesta análise, são também consideradas algumas orientações resultantes de instrumentos de soft law sobre a forma de processamento desta fase pelas entidades adjudicantes. A final, conclui-se que a abordagem europeia quanto à regulamentação da fase de planeamento não parece ser suficiente para potenciar os efeitos positivos que um efetivo planeamento pode ter nas restantes fases da contratação pública.

1 Doctorando em la Facultad de Derecho de la Universidade Católica Portuguesa, Escola do Porto, Porto, Portugal. Bolseiro de Doutoramento - Fundação para a Ciência e Tecnologia, Portugal. Correo-e: jefarialopes@gmail.com. Enlace ORCID: https://orcid.org/00000002-9938-5646. Fecha de recepción: 20 de febrero de 2020. Fecha de modificación: 10 de agosto de 2020. Fecha de aceptación: 20 de septiembre de 2020. Para citar el artículo: FARIA LOPES, JORGE, "La regulación de la fase de planeación de la contratación pública: reflexiones sobre el régimen legal y las directrices del derecho europeo", Revista digital de Derecho Administrativo, Universidad Externado de Colombia, n. ${ }^{\circ} 25,2021$, pp. 255-284. DOI: https://doi.org/10.18601/21452946.n25.08. 
Palavras-chave: planeamento, preparação, anúncios de pré-informação, consultas preliminares ao mercado.

\section{La regulación de la fase de planeación de la contratación pública: reflexiones sobre el régimen legal y las directrices del derecho europeo}

\section{RESUMEN}

El artículo busca resaltar la relevancia de la fase de planificación para lograr los propósitos de las directivas de contratación pública y examinar las regulaciones que abordan de forma expresa la fase de planeación, es decir, las normas relativas a avisos de información previa y consultas preliminares de mercado. El análisis también considera algunas pautas sobre los aspectos principales que deben tenerse en cuenta al abordar la fase de planeación. Se argumenta que el enfoque regulatorio europeo para la fase de planeación es insuficiente para mejorar los impactos positivos que una planificación efectiva puede tener en el resultado de la contratación pública.

Palabras clave: planeación, preparación, avisos de información previa, consultas preliminares de mercado.

\section{The Regulation of the Planning Phase of Public Procurement: Reflections on the Legal Regime and Guidelines of European Law}

\section{ABSTRACT}

This paper seeks to highlight the impact of planning on achieving the main purposes of the European Directives on public procurement, and to examine their rules pertaining to the planning phase and preliminary information notices and market consultations. It also examines some of the guidelines on key aspects to consider when undertaking the planning phase. This research argues that the European regulatory approach to the planning phase is insufficient to enhance the positive impacts that effective planning may have on the outcome of public procurement.

Keywords: Planning, Preparation, Prior Information Notices, Preliminary Market Consultations. 


\section{INTRODUÇÃO}

A fase de planeamento não tem merecido particular atenção por parte do legislador europeu no domínio da regulamentação da contratação pública por via das Diretivas de contratação pública ${ }^{2}$. Desde a década de 70 , com a primeira geração de Diretivas, o foco regulamentador da atividade de contratação pública tem vindo a incidir na procedimentalização da escolha do operador de mercado, num quadro normativo dirigido à construção do mercado único, em obediência a princípios de não discriminação, transparência e concorrência. Porém, o procedimento de adjudicação conducente à escolha do operador hoje extensamente normativizado pelo direito europeu pressupõe sempre uma prévia atividade preparatória das entidades adjudicantes. É neste momento inicial, a que chamaremos fase de planeamento, que, logicamente, a entidade adjudicante planeia a sua ação futura, definindo os passos nucleares sobre "o que", "para quando" e "como fazer para" contratar.

O planeamento traduz o "processo para determinar uma apropriada ação futura através de uma sequência de escolhas ${ }^{113}$ e que serve o propósito de aumentar a racionalidade e eficiência da ação ${ }^{4}$. Neste sentido, o planeamento consubstancia a necessária metodologia prévia à tomada da decisão de contratar no sentido de potenciar a sua racionalidade, transparência e, a final, a própria legalidade da decisão, em detrimento de ação não planeada conducente, no limite, à arbitrariedade, opacidade e ilegalidade da decisão administrativa.

Assim, atenta a inquestionável importância prática que, por imperativo lógico, a diligente condução da fase de planeamento possui para o sucesso das fases de adjudicação e execução dos contratos públicos, propomo-nos, em traços necessariamente sucintos, realizar uma primeira abordagem crítica à regulamentação do planeamento, circunscrita à análise das normas da Diretiva 2014/24/UE e instrumentos de soft law europeu que expressamente se dirigem à ordenação de aspetos relacionados com a condução da fase de planeamento pelas entidades adjudicantes.

Neste contexto, iremos, no plano metodológico, num primeiro passo, enquadrar a relevância jurídica da atividade administrativa desenvolvida na fase de planeamento e a sua relação com a consecução dos objetivos subjacentes

2 Neste sentido, embora ainda antes da reforma de 2014, cf. Martin Trybus, Roberto Caranta e Gunilla Edelstam, "Introduction", in Martin Trybus, Roberto Caranta e Gunilla Edelstam, (eds.), EU Public Contract Law. Public Procurement and Beyond, Bruxelas: Bruylant, 2013, p. 48: "The first phase, defining the need of the public entity or utility, is largely unaffected by EU Law. National, regional and local constitutional rules regulating the budget and decision making provide the only relevant legal frameworks bere. This might change with an emergence of an economic government for the EU or the Eurozone but currently there is no EU Law on this first phase".

3 Cf. Paul Davidoff e Thomas A. Reiner, "A Choice of Theory of Planning", in Andreas Faludi (ed.), A Reader in Planning Theory, Oxford: Pergamon Press, 1973, p. 11. 
às Diretivas de contratação pública. Num segundo passo, faremos uma apreciação crítica das normas europeias atinentes aos anúncios de pré-informação e às consultas preliminares ao mercado, destacando aspetos problemáticos da sua formulação e aplicação, e enunciando algumas boas práticas indicadas pela Comissão Europeia em instrumentos de soft law sobre a forma de processamento das consultas preliminares ao mercado. Num último passo, terminaremos com notas conclusivas sobre os tópicos abordados ao longo do texto.

\section{A RELEVÂNCIA JURÍDICA DA FASE DE PLANEAMENTO E A SUA RELAÇÃO COM OS OBJETIVOS DO DIREITO EUROPEU DA CONTRATAÇÃO PÚBLICA}

A escassa regulamentação europeia dirigida à fase de planeamento, associada à crescente perceção e proclamação pela Comissão Europeia da sua relevância decisiva para o sucesso da condução e dos resultados da contratação pública ${ }^{5}$, revela, a nosso ver, um paradoxo no discurso político-legislativo europeu neste domínio. Este paradoxo sai reforçado quando existem dados do Tribunal de Contas Europeu que explicitamente evidenciam que o maior número de erros graves cometidos pelas entidades adjudicantes acontece na fase prévia ao procedimento adjudicatório propriamente dito, e que destes erros resultam prejuízos na prossecução dos desígnios europeus clássicos de abertura e construção do mercado único da contratação pública ${ }^{6}$.

A desvalorização do planeamento, quer pelo legislador europeu, quer pelas entidades adjudicantes no desenvolvimento das suas atividades de contratação, torna questionável a efetiva mais valia das orientações da Comissão Europeia sobre a fase de planeamento por via de instrumentos de soft law ${ }^{7}$, não vinculativos para as entidades adjudicantes. Aliás, a ausência de garantia de realização do planeamento através de regras legais tem vindo a ser apontada pelo Banco

5 Cf. European Commission, Public Procurement Guidance for Practitioners, February 2018. Disponível em: https://ec.europa.eu/regional_policy/sources/docgener/guides/public_procurement/2018/guidance_public_procurement_2018_pt.pdf [consultado em 27/03/19]: "The preparatory phase of a procurement procedure aims to design a robust process for delivering the required works, services or supplies. It is by far the most crucial stage of the process because the decisions made during this phase will shape the success of the whole procedure" (p. 16).

6 Cf. Tribunal de Contas Europeu, Relatório Especial "Devem intensificar-se os esforços para resolver os problemas relacionados com a contratação pública nas despesas da Coesão da União Europeia", Anexo III, União Europeia, 2015, p. 52. Neste Relatório, identificam-se os erros de divisão artificial do objeto contratual para evitar a aplicação de procedimentos abertos à concorrência, de adoção de ajustes diretos sem fundamento legal para o efeito, e a escolha de procedimentos pré-contratuais inadequados.

7 Cf. European Commission, Public Procurement Guidance for Practitioners, op. cit. 
Mundial como uma das razões para que esta fase seja absolutamente ignorada pelos eleitos políticos e agentes administrativos ${ }^{8}$.

É certo que o planeamento representa uma atividade administrativa tipicamente interna das entidades adjudicantes dos Estados Membros, que integra espaços de definição política da ação e de exercício de poderes discricionários, a preservar pela União Europeia no exercício das suas competências legislativas em matéria de contratação pública, em obediência ao princípio da subsidiariedade ${ }^{9}$. Este aspeto será porventura suficiente para explicar a renitência do legislador europeu em ocupar-se destas matérias, e assim condicionar a discricionariedade estratégica ${ }^{10}$ de planeamento das entidades adjudicantes.

Ainda assim, a verdade é que o direito europeu já regulamenta atividades tipicamente internas das entidades adjudicantes, como, por exemplo, o processo de cálculo do valor do contrato, ou a configuração fracionada ou única do objeto do contrato pretendido celebrar. A razão de ser é simples: todas as ponderações e decisões administrativas que direta ou indiretamente possam limitar indevidamente a escolha do operador económico - restringindo as oportunidades de acesso ao mercado único dos contratos públicos por via da discriminação em razão da nacionalidade - são conformadas pelas normas de harmonização das Diretivas de contratação pública, em obediência à sua a ratio legis originária ${ }^{11}$.

Neste contexto, uma eventual regulamentação europeia harmonizadora de aspetos estruturantes da fase de planeamento por via da definição de standards mínimos vinculativos e orientadores da atividade das entidades adjudicantes dos Estados Membros, não se traduziria numa atuação à margem das competências da União Europeia. Esta eventual regulamentação seria, aliás, congruente com a instalada prática de crescente regulamentação europeia da contratação pública, assente na aparente desconfiança do legislador europeu na capacidade e vontade das entidades adjudicantes dos Estados Membros de cumprirem os objetivos europeus neste domínio ${ }^{12}$.

8 Cf., por exemplo, World BAnK, Uganda Country Procurement Assessment Report (CPAR), vol. II, Main Findings and Recommendations, 2004: The reasons for the lack of procurement planning must be found in 1) Lack of understanding of the value of proper planning and 2) Lack of emphasis on planning in enforcement of the rules.

9 Cf. artigo $5 .^{\circ}$ do Tratado da União Europeia e artigo $4 .^{\circ}$ do Tratado sobre o Funcionamento da União Europeia.

10 Cf. Pedro Gonçalves, Direitos dos Contratos Públicos, 2. ${ }^{a}$ ed. Almedina, 2018, pp. 392-400.

11 Neste sentido, cf. Sue Arrowsmith, "The purpose of the EU Procurement Directives: Ends, Means and the Implications for National Regulatory Space for Commercial and Horizontal Policies", in Cambridge Yearbook of European Legal Studies, vol. 14, Hart, 2012, pp. 6-29; Peter Kunzlik, "Neoliberalism and the European Public Procurement Regime", in Cambridge Yearbook of European Legal Studies, vol. 15, Cambridge: Cambridge University Press, 2013 , p. 335.

12 Neste sentido, cf. Steen Treumer, "Evolution of the EU Public Procurement Regime: The New Public Procurement Directive", in: François Lichère, Roberto Caranta \& Steen 
Neste sentido, verifica-se que a reforma das Diretivas de 2014 incorpora já alguns passos inovadores na regulamentação europeia do planeamento através do mecanismo das consultas preliminares ao mercado, tendo em vista auxiliar as entidades adjudicantes na estruturação do seu planeamento. Estes passos deixam, na nossa perspetiva, antever em futuras reformas uma maior incursão regulamentadora neste domínio. Aliás, como já foi referido, a recente produção de diversos instrumentos de soft law pela Comissão Europeia que recomendam a adoção de condutas de planeamento representa um sinal importante quanto à percȩ̧ão dos órgãos institucionais europeus sobre a crescente relevância jurídico-prática desta fase e do impacto que a mesma possui em todo o ciclo da contratação pública, inclusivamente na própria medida da abertura do mercado dos contratos públicos ${ }^{13}$.

Com efeito, em linha com a visão da Comissão sobre a importância de planear adequadamente a contratação pública, afigura-se-nos que o modo de execução do planeamento pela entidade adjudicante influi de forma decisiva no alcance dos objetivos inerentes à regulamentação europeia. De facto, o planeamento atempado da contratação pública, nas vertentes de identificação estratégica das necessidades de aquisição, e de seleção do curso de ação mais adequado para as satisfazer, representa um decisivo instrumento para maximizar a concretização do objetivo genético do direito europeu de promoção do acesso não discriminatório dos operadores de mercado dos Estados Membros ao mercado único dos contratos públicos. Em nosso entender, o planeamento adequado promove a maximização deste objetivo das seguintes formas:

1) A atividade de planeamento atempado permite, em certas circunstâncias, flexibilizar os procedimentos através da respetiva aceleração da tramitação, por via da efetiva redução de prazos para a apresentação de propostas ${ }^{14}$ ou da própria otimização no cumprimento das formalidades legais e, consequentemente, de todo o calendário de implementação do contrato, o que pode significar um menor custo de transação para os operadores económicos e, consequentemente, um maior acesso potencial dos mesmos ao mercado ${ }^{15}$;

2) O planeamento atempado da contratação potencia, não apenas a correta utilização de estratégias de contratação agregada com aproveitamento de economias de escala, como também a correta utilização de estratégias de contratação desagregada pela divisão em lotes, com recurso a procedimentos

Treumer (eds.), Modernising Public Procurement: The New Directive, Denmark: DJOF Publishing, 2014, p. 10.

13 Cf. European Commission, Public Procurement Guidance for Practitioners, op. cit., p. 16.

14 Por via de anúncios de pré-informação, como será desenvolvido adiante.

15 Neste sentido, cf. Pedro Telles and Luke R. A. Butler, "Public Procurement Award Procedures in Directive 2014/24/EU", in François Lichère, Roberto Caranta \& Steen Treumer (eds.), Modernising Public Procurement: The New Directive, Denmark: DJOF Publishing, 2014, p. 138. 
abertos à concorrência de mercado. Neste último ponto, o planeamento previne condutas de divisão artificial dos objetos dos contratos tendentes a evitar a adoção de procedimentos abertos à concorrência ${ }^{16}$;

3) O planeamento atempado potencia a prevenção da escolha ilegal de procedimentos fechados à concorrência de mercado - em particular o ajuste direto fundado em inexistente urgência imperiosa e os procedimentos com tramitação acelerada fundados em razões de urgência $^{17}$-, na medida em que evita que as entidades adjudicantes sejam confrontadas com necessidades de contratar em momentos em que não possuam o tempo adequado para tramitar os mais "longos" procedimentos abertos à concorrência, em prejuízo, portanto, do acesso ao mercado por parte dos operadores ${ }^{18}$.

Por outro lado, note-se que o planeamento não é apenas instrumental à consecução dos objetivos genéticos do direito europeu, mas também à prossecução dos mais recentes objetivos políticos europeus de sustentabilidade, inovação e de eficiência na utilização de fundos públicos expressamente previstos ${ }^{19}$ na Diretiva na reforma 2014. De facto, apenas com um planeamento com suficiente margem de antecipação se torna possível ter o tempo adequado e a consequente alocação dos recursos necessários para poder desenhar estratégias de sustentabilidade ambiental ${ }^{20}$ a incorporar em sede de especificações técnicas e de condições de execução do contrato, ou nos fatores de avaliação, bem como para poder preparar de forma conveniente a adoção das complexas parcerias para a inovação ${ }^{21}$.

16 Cf. European Commission, Public Procurement Guidance for Practitioners, op. cit., p. 16

17 Sobre a necessidade de as entidades adjudicantes deverem considerar o tempo necessário à tramitação das formalidades adjudicatórias como forma de evitar o recurso ao ajuste direto fundado em motivos de urgência imperiosa inadmissível, cf. SuE ArRowsmith, The Law of Public and Utilities Procurement, Regulation in the EU and the UK, vol. I, 3. ${ }^{\text {a }}$ ed., UK: Sweet \& Maxwell, 2014, p. 1075. Sobre a relação entre o planeamento e a tramitação acelerada de procedimentos com base em razões de urgência, cf. Sune Troels Poulsen, Peter StiG Jakobsen and Simon Evers Kalsmose-HjelmborG, EU Public Procurement Law, 2. ${ }^{\text {a }}$ ed., Denmark: DJOF Publishing, 2012, p. 377.

18 Aspeto como sendo um dos erros mais frequentes detetados na fase prévia à adjudicação pelo Tribunal de Contas Europeu. Cf. Tribunal de Contas Europeu, Relatório Especial "Devem intensificar-se os esforços...", op. cit., p. 52.

19 Sobre a consagração expressa do objetivo da eficiência, vejam-se os considerandos 2, 47 , 52, 91, 121, da Diretiva 2014/24/UE.

20 Cf. European Commission, Buying Green! A Handbook on Green Public Procurement, 3. ${ }^{a}$ ed., 2016 p. 10.

21 Cf. European Commission, Commission Notice Guidance on Innovation Procurement, 2018, p. 30, Oana Pantilimon Voda and Caroliene Jobse, "Rules and Boundaries Surrounding Preliminary Market Consultations in Innovation Procurement: Understanding and Addressing the Legal Risks", European Procurement \& Public Private Partnerships Law Review, vol. 11, n. ${ }^{\circ} 3$. 
Por seu turno, o planeamento encontra-se intimamente relacionado com a prossecução de uma contratação pública mais eficiente ${ }^{22}$, seja numa perspetiva de eficiência administrativa de otimização da condução do procedimento, seja numa perspetiva da eficiência do resultado (value for money) a obter por via do contrato público ${ }^{23}$. Desde logo, como a Comissão Europeia já sublinhou, a rigorosa definição das necessidades na fase de planeamento previne a ineficiência resultante de despesa pública com a aquisição precipitada de bens ou serviços que se revelem a posteriori desnecessários por falta de uma rigorosa avaliação prévia na fase de planeamento ${ }^{24}$.

$\mathrm{Na}$ medida em que previna a divisão artificial do contrato ou a escolha ilegal de procedimentos fechados à concorrência, o planeamento também serve o propósito de prevenir ineficiências resultantes da atribuição de contratos a operadores sem o prévio crivo concorrencial, ou a repetição da tramitação de procedimentos resultantes de eventual anulação por ilegalidade. De outro ângulo ainda, é no planeamento que devem ser definidas as estratégias da contratação pública que permitam uma eficiente utilização dos recursos públicos por via da contratação centralizada e/ou através da utilização de acordos-quadro.

Por último, a atividade de planeamento serve igualmente o propósito instrumental de registo do processo racional de tomada da decisão de contracting out, o que potencia o alcance de uma maior transparência e integridade da atividade de contratação pública, prevenindo fenómenos de corrupção. Neste âmbito, o planeamento fomenta a maior accountability na utilização dos fundos públicos pela entidade adjudicante, uma vez que faz parte do planeamento justificar as opções tomadas para alcançar os objetivos estratégicos definidos o que, a final, contribui para o reforço da fundamentação da própria decisão de contratar.

22 Sobre o objetivo da eficiência no direito europeu da contratação pública, cf. MARIO E. Comba, "Variations in the scope of the new EU public procurement Directives of 2014: Efficiency in public spending and a major role of the approximation of laws", in François Lichère, Roberto Caranta \& Steen Treumer (eds.), Modernising Public Procurement: The New Directive, Denmark: DJOF Publishing, 2014, pp. 29-48.

23 Sobre estas duas perspetivas do objetivo da eficiência nos regimes de contratação pública, cf. Sue Arrowsmith, "Public Procurement Regulation: An introduction", in The EU Asia Inter University Network for Teaching and Research in Public Procurement Regulation, 2010, p. 4. Vejase, em geral, sobre o objetivo da eficiência nos sistemas de contratação pública, STEVEN Kelman, Procurement and Public Management, The Fear of Discretion and the Quality of Government Procurement, Washington: Aes Press, 1990, p. 11; Peter TrePte, Regulating Procurement: Understanding the Ends and Means of Public Procurement Regulation, Oxford: Oxford University Press, 2004, p. 59.

24 Cf. European Commission, Public Procurement Guidance for Practitioners, op. cit., p. 19. 


\section{AS NORMAS EUROPEIAS SOBRE O PLANEAMENTO DA CONTRATAÇÃO PÚBLICA}

Como resulta do que se referiu, a atividade de planeamento assegura que sejam feitas, de forma atempada, as ponderações administrativas que influenciam todo o ciclo $^{25}$ de contratação pública, desde a formação à implementação do contrato, como o apuramento da necessidade de contratar, a seleção do tipo de contrato e a definição do objeto contratual ${ }^{26}$, único ou fracionado em lotes ${ }^{27}$, o cálculo do respetivo valor e a escolha do procedimento adjudicatório.

$\mathrm{Na}$ reforma das Diretivas de contratação pública ${ }^{28}$ de 2014, foram dados alguns passos na regulamentação da fase de planeamento - ou seja, na agora expressamente prevista fase de 'preparação' - por ordem aos racionais de maximização do acesso dos operadores económicos ao mercado único da contratação pública, e de maior responsabilização das entidades adjudicantes na preparação informada dos seus contratos públicos. Nesta última perspetiva, como vimos, verifica-se ainda a reserva compreensível do legislador europeu em harmonizar aspetos relativos ao conteúdo de uma atividade administrativa de pendor

25 Neste sentido, cf. Sue Arrowsmith, "Public Procurement Regulation: An introduction", op. cit., p. 1: Sobre o significado do planeamento no ciclo da contratação pública, veja-se a noção cristalina apresentada pela Autora: "There are three phases of the public procurement process: a) Deciding which goods or services are to be bought and when (procurement planning), b) The process of placing a contract to acquire those goods or services which involves, in particular, choosing who is to be the contracting partner and the terms on which the goods or services are to be provided; and c) The process of administering the contract to ensure effective performance. [... . Obviously the three stages need to be closely integrated and regarded as separate phases of a cobesive 'cycle'".

26 Cf. Martin BurGi, "Specifications", in Martin Trybus, Roberto Caranta and Gunilla Edelstam (eds.), EU Public Contract Law. Public Procurement and Beyond, EU Public Contract Law. Public Procurement and Beyond, Bruxelas: Bruylant, 2013, p. 78: "Probably one of the earliest stages of public procurement constitutes one of the most important and influential ones: the contract specifications. Taking effect from the outset of each procurement procedure, the rules on specifications virtually establish the base for important subsequent stages and are linked to other important issues of public procurement procedures".

27 Sobre a relevância da decisão de divisão do contrato em lotes, cf. GianCARLO SPAGNOLO and Christopher yukins, "Lots - The Economics and Legal Challenges of Centralized Procurement. Colloquium", in Gustavo Piga, and Tunde Tatrai (eds.), Public Procurement Policy, London: Routledge, 2016, p. 96: "The design of lots is the most important decision in procurement, as it (a) 'defines the object' procured, and (b) it 'defines the market', who will be able to supply, bow much competition there will be, etc. Everything else in procurement is a consequence of that decision"; GIAN Luigr Albano, Competition in Public Procurement Markets, Paper for Working Party on Competition and Regulation $\mathrm{OECD}, 2017$, p. 10: "Whether, and if so, how, to split a procurement contract into different lots, is one of the most important decisions in designing a competitive procurement process. By affecting the number and the type of firms that are able to compete, 'lots design' can have a dramatic impact on the intensity of competition in the market, and bence for current and potential future contracts".

28 Diretiva 2014/23/UE, Diretiva 2014/24/UE e Diretiva 2014/25/UE, do Parlamento Europeu e do Conselho, de 26 de fevereiro de 2014. Conforme referido na introdução, a análise subsequente incidirá sobre o regime constante da Diretiva 2014/24/UE, apesar de alguns pontos serem também objeto da regulamentação na Diretiva dos setores especiais. 
interno, por vezes sigilosa e marcadamente politizada, das entidades adjudicantes dos Estados Membros, em obediência ao princípio basilar da subsidiariedade no exercício das competências da União ${ }^{29}$.

Neste contexto, a inovadora consagração na Diretiva 2014/24/UE do mecanismo das consultas preliminares ao mercado ${ }^{30}$ visa promover, a montante da escolha do procedimento adjudicatório, a maior certeza jurídica e rigor nas tarefas preparatórias de definição do objeto contratual e do cálculo do respetivo valor, em sintonia com aquilo que o mercado pode em determinado momento efetivamente oferecer para satisfazer a necessidade de contratar detetada ${ }^{31}$.

Outro sinal forte de relevância normativa do planeamento da contratação surge no regime europeu de enquadramento procedimental do fracionamento do objeto contratual, nas normas sobre o cálculo do valor do contrato ${ }^{32}$, e no regime da divisão dos contratos em lotes ${ }^{33}$, apesar de aquelas não se enquadrarem sistematicamente na 'fase de preparação' expressamente consagrada na Diretiva 2014/24/UE. Nesta sede, em particular nas regras de agregação do valor do contrato, também é possível identificar um conjunto de parâmetros normativos dirigidos a conformar a atividade administrativa de planeamento das necessidades aquisitivas presentes e futuras, tendo em vista prevenir situações de divisão artificial do objeto contratual, com a finalidade de evitar a aplicação dos procedimentos adjudicatórios previstos nas Diretivas para contratos de valor superior aos limiares europeus.

Além destes aspetos, o regime dos anúncios de pré-informação constante da Diretiva 2014/24/UE revela também a intenção do legislador europeu de regulamentar a atividade de planeamento das entidades adjudicantes no sentido de estimular a visão estratégica que permita a partilha de informação para, designadamente, fomentar o acesso de operadores ao mercado ${ }^{34}$, ainda que com um alcance normativo de obrigatoriedade muito limitado. Como será adiante desenvolvido, trata-se aqui de estabelecer uma faculdade de anunciar "intenções de compra", que serve um propósito informativo de assistência aos operadores sobre as eventuais necessidades aquisitivas das entidades adjudicantes, propósito este que pode ser complementado pelo mecanismo das consultas preliminares ao mercado, bem como uma função de flexibilização

29 Cf. artigo 5. ${ }^{\circ}$ do Tratado da União Europeia.

30 Cf. artigo $40 .^{\circ}$ da Diretiva 2014/24/UE.

31 Sobre esta matéria, veja-se OECD/SIGMA, Market Analysis, Preliminary Market Consultations, and Prior Involvement of Candidates/Tenderers, OECD/SIGma, 2016, p.3; Sue Arrowsmith, The Law of Public..., op. cit., p. 650.

34 Em sentido idêntico, sobre a recomendação de publicação de planos anuais de contratação pública, Cf. European Commission, Publish Annual Procurement Plans, E-Library on Public Procurement Good Practices. Disponível em https:/ec.europa.eu/regional_policy/sources/ good_practices/GP_fiche_12.pdf. 
dos procedimentos adjudicatórios através da redução de prazos para a apresentação de candidaturas/propostas.

O direito europeu prevê que estes mecanismos possam ser utilizados para efeitos de planeamento plurianual de contratos apenas nos casos de serviços sociais e de outros setores específicos ${ }^{35}$. A propósito do planeamento plurianual, é interessante notar que o regime europeu de standards mínimos se distancia de outros sistemas jurídicos como o norte-americano ${ }^{36}$, no qual se permite e incentiva a sua efetivação com um âmbito mais alargado, ainda que com diferentes graus de vinculatividade quanto à obrigação de publicação do anúncio e do respetivo conteúdo.

Esta regulamentação de aspetos que devem ser considerados pelas entidades adjudicantes na fase "a montante" da abertura do procedimento ${ }^{37}$ de contratação pública representa, de outro ângulo, um sinal de reforço das ponderações administrativas a revelar na fundamentação da decisão de contratar, no sentido de esta ser mais transparente. O reforço da transparência alinha-se com o propósito da utilização mais responsável e eficiente de fundos públicos na contratação pública que, em nosso entender e como vimos acima de forma sumária, traduz um dos inovadores objetivos políticos visados na reforma das Diretivas de 2014.

\subsection{OS ANÚNCIOS DE PRÉ-INFORMAÇÃO}

O anúncio do contrato representa, no direito europeu da contratação pública $^{38}$, o ato que inicia a fase de formação do contrato, ou seja, o início dos procedimentos administrativos tendentes à adjudicação de uma proposta e à subsequente celebração de um contrato público. Naturalmente, esta regra não se aplica aos procedimentos de ajuste direto, os quais são iniciados com a decisão de contratar exteriorizada no convite dirigido à (s) entidade (s) convidada (s). Por seu turno, esta terminologia europeia sobre o ato propulsivo do procedimento adjudicatório carece de algumas explicações adicionais sobre as decisões administrativas que subjazem ao anúncio do contrato, sobre as quais não nos vamos ocupar neste texto ${ }^{39}$.

35 Cf. artigo $48 .^{\circ}, 2$, da Diretiva 2014/24/UE.

36 Cf., no regime norte-americano, ponto 5.404 da FAR: "To assist industry planning and to locate additional sources of supply, it may be desirable to publicize estimates of unclassified long-range acquisition requirements. Estimates may be publicized as far in advance as possible".

37 Esta fase situa-se cronologicamente em momento anterior à "abertura do procedimento", conforme a terminologia utilizada na norma do artigo $40^{\circ}$, primeiro parágrafo, da Diretiva 2014/24/UE.

38 Cf. artigo 49. ${ }^{\circ}$ da Diretiva 2014/24/UE. Cf. Michael SteiniCKe and Peter L. Vesterdof, Brussels Commentary on EU Public Procurement Law, Bruxelas: Nomos, 2018, p. 575.

39 No ordenamento jurídico português, o procedimento adjudicatório inicia-se com decisão de contratar - artigo 36. ${ }^{\circ},{ }^{\circ}{ }^{\circ} 1$, do Código dos Contratos Públicos -, a qual representa 
Diferente do anúncio do contrato é o designado "anúncio de pré-informação" publicado no Jornal Oficial da União Europeia ou no perfil do adquirente, e que pode assumir diferentes funções no quadro do direito europeu. Desde logo, o anúncio de pré-informação pode servir de meio facultativo $^{40}$ de anúncio de futuras intenções de contratação para um determinado período temporal. A entidade adjudicante dá a conhecer por este meio, de forma antecipada, as suas necessidades aquisitivas ao mercado no sentido de providenciar informação útil aos operadores para, atempadamente, poderem preparar a sua participação nos futuros procedimentos ${ }^{41}$. Nada se dispõe na Diretiva 2014/24/UE acerca da atividade material de planeamento levada a cabo pela entidade adjudicante, a qual, porém, logicamente precede e suporta a publicação deste anúncio de pré-informação, designadamente no que respeita às tarefas de apuramento da necessidade aquisitiva, de seleção do tipo de contrato, de estimativa do respetivo valor, de escolha do procedimento e de calendarização do seu início. É, aliás, ilustrativa desta asserção a terminologia utilizada no artigo $48 .^{\circ},{ }^{\circ} .^{\circ}$ 1, da Diretiva 2014/24/UE, quando se refere:

- "As autoridades adjudicantes podem dar a conhecer os seus concursos programados através da publicação de um anúncio de pré-informação". - itálico nosso.

Como nota prévia, cumpre referir que a versão portuguesa desta norma da Diretiva não se afigura precisa: não se trata, em rigor, de pré-anunciar os concursos, mas sim os contratos a formar através de diferentes procedimentos, entre eles o concurso público e/ou o concurso limitado por prévia qualificação. $\mathrm{O}$ termo "programa" no sentido de "plano" é, aliás, utilizado na versão portuguesa deste preceito de forma descontextualizada em relação aos considerandos e normas da Diretiva, uma vez que se utiliza o termo "planeamento", e não "programação", em sede de considerandos e nas disposições sobre consultas preliminares ao mercado, como veremos de seguida.

Por outro lado, na versão inglesa da Diretiva, o planeamento surge também a propósito desta norma sobre anúncios de pré-informação. Note-se que a versão inglesa contém um sentido ligeiramente diferente em relação à versão

simultaneamente o culminar do procedimento prévio de preparação onde a fase de planeamento se insere. Sobre a decisão de contratar, na doutrina portuguesa mais recente, cf., entre outros, Pedro Gonçalves, Direitos dos Contratos Públicos, op. cit. pp. 392-400, Miguel Assis Raimundo, A formação dos contratos públicos - Uma concorrência ajustada ao interesse público, Lisboa: AAFDL, 2013, pp. 771-780; Pedro Fernández SánCHEZ, Direito da Contratação Pública, vol. I, Lisboa: AAFDL, 2020, pp. 559-566; Juliana Ferraz Coutinho, "A decisão de contratar e as suas circunstâncias", Revista dos Contratos Públicos, n. ${ }^{\circ} 23,2020$, pp. 135-148.

40 Sobre o carácter facultativo do anúncio de pré-informação, cf. MichaEl STEINICKE and Peter L. Vesterdof, EU Public Procurement Law, op. cit., p. 573.

41 Cf. Sue Arrowsmith, The Law of Public and Utilities Procurement..., op. cit., p. 671; Michael Steinicke and Peter L. Vesterdoof, EU Public Procurement Law, op. cit., p. 572. 
portuguesa e que, a nosso ver, se revela tecnicamente mais preciso, uma vez que se refere ao anúncio como meio de publicitar intenções de contratação planeada - seja ela de bens, serviços e/ou empreitadas, e por via de diferentes procedimentos -, quando se determina:

- "Contracting authorities may make known their intentions of planned procurement through the publication of a prior information notice". - itálico nosso.

Decorre da letra do preceito que a publicação do anúncio de pré-informação pressupõe que a contratação já tenha sido planeada. Aliás, veja-se que do anúncio informativo deve constar a indicação da data de publicação do anúncio do contrato ${ }^{42}$, ou seja, do momento em que se prevê iniciar o procedimento adjudicatório, o que pressupõe que, em sede de planeamento, se tenha previamente estimado o tempo necessário à preparação das peças do procedimento e ao envio do anúncio do concurso para publicação.

Assim, o anúncio de pré-informação traduz um "ponto de chegada" da prévia atividade de planeamento, a qual não é coberta pelo âmbito de regulamentação do direito europeu, apesar de ser um pressuposto da sua aplicação. Por outras palavras, os anúncios de pré-informação traduzem o resultado de uma atividade de planeamento de contratação pública, apresentado de forma sintética e no qual se expressa uma intenção de futura contratação, sem carácter de obrigatoriedade.

O conteúdo do "plano sintetizado" no anúncio de pré-informação é minimalista no sentido de apenas conter uma lista resumida de características finais dos contratos pretendidos sem, portanto, qualquer exigência de justificação das opções planeadas ou de condução do próprio planeamento pelas entidades adjudicantes. O regime europeu dos anúncios de pré-informação é, portanto, pouco denso, sendo destituído das pretensões de abrangência e/ou detalhe de outros regimes mais prescritivos sobre a condução da própria atividade de planeamento, como por exemplo o norte-americano ${ }^{43}$.

No leque de informação a preencher neste anúncio de pré-informação, consta a indicação sobre se a entidade adjudicante é, ou não, uma central de compras, o local de entrega dos bens, serviços ou da empreitada, a breve descrição do contrato, a data estimada para a publicação do anúncio de concurso relativo ao contrato planeado e "quaisquer outras informações relevantes". A escassez de densidade da informação a constar deste anúncio de meras intenções de contratação no espaço alargado do mercado único, associado à sua natureza

42 Cf. Anexo v, Parte B, ponto 8, da Diretiva 2014/24/UE: "data(s) estimada(s) para a publicação de um anúncio ou anúncios de concurso relativo(s) ao(s) contrato(s) referido(s) no anúncio de pré-informação".

43 Veja-se a este propósito o regime de planeamento da contratação pública constante da Federal Acquisition Regulation, Part 7 "Acquisition Planning". 
facultativa, tem suscitado questões sobre a sua parca utilização pelas entidades adjudicantes e efetiva utilidade ${ }^{44}$. Neste sentido, existe inclusivamente evidência da muito escassa utilização deste meio em situações de contratação de infraestruturas de elevado valor e com elevada complexidade técnica em diferentes sistemas internacionais, onde naturalmente se justificaria o préanúncio para efeitos de preparação atempada pelos operadores, por exemplo no domínio de infraestruturas desportivas ${ }^{45}$.

Além do referido, cumpre referir que a utilidade dos anúncios de préinformação no direito europeu encontra-se muito ligada à sua segunda função, ou seja, à possibilidade de permitir a redução do prazo para apresentação de propostas, de 30 para 15 dias $^{46}$. Para obter este concreto efeito, a publicação do anúncio de pré-informação torna-se obrigatória ${ }^{47}$, conforme é previsto nos artigos $27 .^{\circ}$, n. $^{\circ} 2$, e $28 .^{\circ}$, n. $^{\circ} 3$, da Diretiva 2014/24/UE, sendo necessário o preenchimento das informações previstas no Anexo $V$, parte $B$, e o envio do anúncio de pré-informação para publicação com a antecedência mínima entre 35 dias e 12 meses em relação à data de anúncio do concurso ${ }^{48}$. Este regime serve o propósito de maior flexibilidade e eficiência na gestão dos procedimentos administrativos pelas entidades adjudicantes, sem comprometer o objetivo de garantia de acesso ao mercado por parte dos operadores ${ }^{49}$.

A redução do calendário de execução ${ }^{50}$ do procedimento pré-contratual visa diminuir os custos de transação e de oportunidade das entidades adjudicantes e dos operadores ${ }^{51}$, os quais se encontram, em larga medida, associados aos longos períodos de tramitação dos procedimentos pelas entidades adju-

44 Neste sentido, a propósito da escassa utilização deste meio no Reino Unido no âmbito dos setores especiais, Cf. Sue Arrowsmith, The Law of Public and Utilities Procurement..., op. cit., p. 672.

45 Neste sentido, cf. Sue Arrowsmith, Ruth Bayley, Anna Gorczynska, Joshua Idoku, Steve Kay, Jorge Faria Lopes, Carlos Sebastian Barreto Cifuentes, Geo Quinot, Ke Ren, AshrafUl-Bari Nobel, Astghik Solomanyan, Izabella Sobieraj, Gábor Soós and Alex Thurston, "Procuring Infrastructure for International Sporting Events: Mapping the Field for IPACS and Beyond", Public Procurement Law Review, vol. 28, n. ${ }^{\circ}$ 6, 2019, p. 271.

46 O prazo de 30 dias pressupõe a tramitação das propostas via eletrónica, caso contrário o standard mínimo é de 35 dias. Cf. artigo 27. ${ }^{\circ}$, n. ${ }^{\circ}$ s 1 e 4, da Diretiva 2014/24/UE.

47 Neste sentido, cf. Michael Steinicke and Peter L. Vesterdof, EU Public Procurement Law..., op. cit., p. 572.

48 Cf. artigo $48 .^{\circ}$, n. $^{\circ} 2$, da Diretiva 2014/24/UE.

49 Cf. Michael Steinicke and Peter L. Vesterdof, EU Public Procurement Law..., op. cit., p. 572.

50 Sobre a relevância do fator tempo na execução do planeamento, cf. Joseph Pegnato, "Assessing Federal Procuring Reform: Has the Procurement Pendulum Stopped Swinging?", in Khi V. Thai (ed)., International Handbook of Public Procurement, New York: Routledge, 2009, p. 118; Timothy G. Hawkins and William A. Muir, "An Exploration of KnowledgeBased Factors Affecting Procurement Compliance", Journal of Public Procurement, vol. 14, n. ${ }^{\circ} 1,2014$, p. 10.

51 Neste sentido, cf. Pedro Telles and Luke R. A. Butler, "Public Procurement Award Procedures in Directive 2014/24/EU", op. cit., p. 138 
dicantes. Neste âmbito, convirá ter presente que a média de duração de um procedimento pré-contratual em todos os Estados Membros, sem contar com o seu planeamento e preparação, atinge 100 dias $^{52}$, o que explica a intenção expressa pelo legislador europeu de encontrar vias de simplificação e flexibilização dos procedimentos, ainda que nem sempre alcançadas ${ }^{53}$.

Por último, como terceira função do anúncio de pré-informação, cumpre ainda referir que, nos termos do disposto no artigo $48 .{ }^{\circ},{ }^{\circ}{ }^{\circ} 2$, da Diretiva 2014/24/ UE, o anúncio de pré-informação também pode servir de anúncio do contrato nos procedimentos de concurso público com fase de negociação e concurso limitado por prévia qualificação adotados por autoridade subcentrais. Esta via de flexibilização permite que a entidade adjudicante publique um anúncio com uma "lista" de contratos em vez de estar limitada a fazê-lo de forma individual, para cada contrato. Aos procedimentos adotados por autoridades centrais, não se aplica esta faculdade por razões ligadas ao Acordo sobre Compras Públicas de que a União Europeia é parte. Diga-se, contudo, que esta via de publicitação é facultativa na sua aplicação ${ }^{54}$, não sendo os Estados Membros obrigados a transpor para os seus ordenamentos jurídicos tal mecanismo ${ }^{55}$.

\subsection{AS CONSULTAS PRELIMINARES AO MERCADO}

A regulamentação europeia inovadora sobre o planeamento da contratação pública assenta, em larga medida, na consagração expressa do regime das consultas preliminares ao mercado. Até à reforma das Diretivas de contratação pública de 2014, as consultas preliminares ao mercado não eram sequer tratadas no "corpo normativo" das Diretivas, apesar de já ser feita referência à possibilidade de as entidades adjudicantes poderem "dialogar" com entidades terceiras em momento anterior ao início do procedimento de formação do contrato. Esta referência foi feita, pela primeira vez, em sede de orientações interpretativas presentes nos considerandos das Diretivas 97/52/CE e 98/4/

52 Cf. European Commission, Single Market Scoreboard, 2018, p. 1., disponível para consulta em https://ec.europa.eu/internal_market/scoreboard/_docs/2019/performance_per_policy_area/public_procurement_en.pdf. Veja-se, também, o estudo da empresa Spend Network, com base em dados recolhidos e analisados entre 2009 e 2013, cf. https://medium. com/understanding-spend/tender-timeframes-cfa0190dc947 [acesso em 15/02/2020].

53 Relativamente à ausência de simplificação procedimental resultante da reforma de 2014 cf. Steen Treumer, "Evolution of the EU Public Procurement Regime: The New Public Procurement Directive", in François Lichère, Roberto Caranta and Steen Treumer (eds.), Modernising Public Procurement: The New Directive, Denmark: DJOF Publishing, 2014, p. 10.

55 No ordenamento jurídico português encontra-se refletida a possibilidade de utilização deste mecanismo, cf. artigo $167 .^{\circ}$, n. $^{\circ} 3$, do Código dos Contratos Públicos. 
CE, por virtude do esforço de alinhamento de regimes ${ }^{56}$ com o disposto no Acordo sobre Compras Públicas ${ }^{57}$ de 1994.

De facto, dispunha-se no considerando 10) da Diretiva 97/52/CE ${ }^{58}$ o seguinte:

- "Considerando que as entidades contratantes podem solicitar ou aceitar pareceres que possam ser utilizados para a preparação de especificações relativas a um determinado contrato, na condição de que esses pareceres não tenham por efeito impedir a concorrência." - itálico nosso.

A possibilidade de diálogo prévio à fase de adjudicação servia, assim, a função circunscrita à obtenção ou aceitação de pareceres para a preparação de especificações técnicas relativas a um determinado contrato, desde que esses pareceres não tivessem por efeito impedir a concorrência. Nada se dizia sobre quem podia ser consultado para fornecer esses pareceres, nem em que condições essa consulta podia ou devia ocorrer.

Além do referido, limitava-se a utilização destes pareceres pelas entidades adjudicantes quando aqueles conduzissem a situações de distorção da concorrência no contexto específico da preparação das especificações técnicas de um contrato. A ideia central que resultava deste considerando era, em suma, a de que não se podia obter ou aceitar pareceres sobre especificações técnicas que, uma vez integrados no caderno de encargos, significassem a restrição indevida dos potenciais operadores interessados no contrato a, no limite, apenas um. Note-se que a redação do Acordo sobre Compras Públicas na versão de 1994 era mais precisa e limitativa, no sentido de proibir a obtenção ou aceitação de pareceres produzidos por entidades que "pudessem ter um interesse comercial no contrato" ${ }^{\prime \prime}$.

56 Cf. Sue Arrowsmith, The Law of Public and Utilities Procurement, Regulation in the EU and the UK, op. cit., p. 651; Michael Steinicke and Peter L. Vesterdof, EU Public Procurement Law - Brussels Commentary, op. cit., p. 516.

57 O artigo VI, 4, da versão do Acordo sobre Compras Públicas de 1994 [GPA] previa: "Entities shall not seek or accept, in a manner which would have the effect of precluding competition, advice which may be used in the preparation of specifications for a specific procurement from a firm that may bave a commercial interest in the procurement" - itálico nosso. Esta disposição já constava do artigo IV, 4, do Agreement on Public Procurement na redação de 1988. Cf. https://www.wto.org/english/tratop_e/gproc_e/gpa_rev_text_1988_e.pdf. [acesso em 13/02/2020].

58 Diretiva relativa à coordenação dos procedimentos de adjudicação nos setores clássicos de serviços, fornecimentos e de empreitadas de obras públicas. O mesmo considerando foi replicado no considerando 13) Diretiva 98/4/CE relativa aos procedimentos de adjudicação nos setores especiais.

59 Cf. artigo VI, 4, Acordo sobre Compras Públicas, 1994 
Em 2004, a possibilidade de consulta ao mercado foi ligeiramente desenvolvida no considerando 8) da Diretiva 2004/18/CE60, no qual se previa o seguinte:

- "Antes da abertura de um processo de adjudicação de um contrato, as entidades adjudicantes podem, recorrendo a um «diálogo técnico», solicitar ou aceitar pareceres que possam ser utilizados para a elaboração do caderno de encargos, na condição de que esses pareceres não tenham por efeito impedir a concorrência". - itálico nosso.

Nesta formulação foi explicitado o momento temporal em que o diálogo técnico podia ter lugar por referência ao momento de "abertura do processo de adjudicação de um contrato", o qual, como vimos, se concretiza com a publicação do anúncio do contrato. Por outro lado, e a nosso ver, alargou-se a função deste diálogo técnico no sentido de se dirigir à aceitação ou obtenção de pareceres para a "elaboração do caderno de encargos", não se restringindo, portanto, à parte das especificações técnicas deste e incluindo também as condições de execução do contrato. Manteve-se, no entanto, a condição de que os pareceres técnicos não poderiam ter por efeito impedir a concorrência.

Repare-se que não se fazia referência na letra destes considerandos a qualquer lastro mais amplo deste diálogo estritamente técnico destinado a preparar a elaboração do caderno de encargos pelas entidades adjudicantes, não se identificando também a quem poderia ser solicitada esse auxílio. A doutrina encarregou-se de atribuir um âmbito mais alargado a estas linhas do considerando da Diretiva no sentido de delas extrair uma orientação permissiva para a condução de uma fase de discussão preliminar com o mercado em momento anterior ao procedimento adjudicatório, num esforço de enquadramento da sua função, assim como da sua relevância jurídica autónoma em face do procedimento de diálogo concorrencial ${ }^{61}$.

Mais tarde, em 2014, o legislador europeu veio desenvolver o tratamento legal dado às consultas preliminares ao mercado, consagrando o mecanismo no âmbito da Secção 1 "Preparação" do Capítulo III "Condução do Procedimento" da Diretiva 2014/24/UE ${ }^{62}$, no âmbito do artigo $40 .^{\circ}$. Dispõe-se neste preceito:

- "Antes da abertura de um procedimento de contratação, as autoridades adjudicantes podem realizar consultas ao mercado, a fim de preparar esse procedimento e de informar os operadores económicos dos seus planos de contratação e respetivos requisitos.

60 Diretiva aplicável aos procedimentos de adjudicação dos contratos dos setores clássicos. Este considerando não era replicado na Diretiva 2004/17/CE aplicável aos procedimentos de adjudicação dos contratos dos setores especiais.

61 Neste sentido, cf. Sue Arrowsmith, The Law of Public and Utilities Procurement, Regulation in the EU and the UK, op. cit., pp. 650-651.

62 Semelhante disposição consta do artigo 58. ${ }^{\circ}$ da Diretiva 2014/25/UE aplicável aos procedimentos de adjudicação dos contratos dos setores especiais, mas estranhamente não existe na Diretiva 2014/23/UE aplicável aos contratos de concessão. 
Para este efeito, as autoridades adjudicantes podem, por exemplo, solicitar ou aceitar pareceres de peritos ou autoridades independentes ou de participantes no mercado que possam ser utilizados no planeamento e na condução do procedimento de contratação, na condição de que esses pareceres não tenham por efeito distorcer a concorrência nem resultem em qualquer violação dos princípios da não discriminação e da transparência". - itálico nosso.

A densificação normativa do mecanismo das consultas preliminares ao mercado na atual redação, de natureza declarativa e clarificadora ${ }^{63}$, afigura-se evidente em face das anteriores redações acima transcritas: no que respeita à sua função, o mecanismo deixa de servir apenas o propósito de elaborar o caderno de encargos, passando a estar afeto a uma função dupla de vocação mais abrangente. Agora, a consulta destina-se a uma função interna de planear e preparar o procedimento pré-contratual num sentido mais genérico, e a uma função externa de informar os operadores de mercado dos planos e requisitos da contratação pública.

A primeira função interna destina-se a auxiliar a entidade adjudicante no processo de apuramento das suas necessidades de aquisição, bem como a possibilidade de as satisfazer através de determinados contratos, em face das condições de mercado existentes. De facto, não raras vezes as entidades adjudicantes pretendem realizar uma determinada tarefa pública, mas não sabem aquilo de que precisam para o efeito, ou desconhecem qual o "estado da arte" no mercado dos bens, serviços ou obras pretendidas, ou, ainda não sabem como o mercado reagiria à adoção do procedimento ${ }^{64}$. Assim, a consulta serve o propósito de a entidade adjudicante aferir da exequibilidade técnica e financeira do contrato pretendido para satisfazer a necessidade no calendário desejado ou imposto, em função das condições de mercado efetivamente existentes, e considerando eventuais experiências passadas sobre as quais exista documentação que possa ser utilizada ${ }^{65}$. A utilização do mecanismo permite corrigir as assimetrias de informação entre as entidades adjudicantes e os operadores de mercado, potenciadoras de atuações ineficientes, para que o desenho do contrato pretendido para satisfazer o interesse público encontre a maior aderência possível ao que o mercado pode oferecer em determinado momento temporal ${ }^{66}$.

Por outro lado, a segunda função externa permite que a entidade adjudicante informe os operadores de mercado das suas pretensões aquisitivas para que aqueles

63 Utilizando esta expressão, cf. Michael Steinicke and Peter L. Vesterdof, EU Public Procurement Law ..., op. cit., p. 516: "The wording can be seen as clarification of the earlier recital and of the case law that has built up around technical dialogue".

64 Cf. Miguel Assis Raimundo, A formação dos contratos públicos, op. cit., pp. 687-688.

65 Cf. OECD/SIGma, Market Analysis, Preliminary Market Consultations, and Prior Involvement of Candidates/Tenderers, OECD/SIGMA, 2016, p.6.

66 Cf. Peter Trepte, Regulating Procurement, op. cit., p. 70 
possam preparar-se da melhor forma para uma eventual participação ${ }^{67}$, à semelhança do que sucede com os anúncios de pré-informação, nos termos acima analisados. Nenhum parâmetro é indicado no artigo $40 .^{\circ}$ quanto ao "tipo" de informação suscetível de ser trocada com os operadores para este propósito, em sede de consulta preliminar ao mercado. Tipicamente, a informação será similar ou aproximada àquela exigida no anúncio de pré-informação, designadamente, a breve descrição do contrato desejado, as condições comerciais praticadas, os dados do local de entrega dos bens, serviços ou da empreitada, ou a data estimada para a publicação do anúncio de concurso relativo ao contrato planeado. Pode admitir-se, como limite estrutural de informação sobre os planos de contratação suscetível de ser comunicada aos operadores no âmbito de uma consulta preliminar, que não seja previamente anunciada ${ }^{68}$, a informação constante do anúncio do concurso a publicitar no Jornal Oficial da União Europeia ${ }^{69}$, convocando-se para o efeito o disposto no artigo 52. ${ }^{\circ}$ da Diretiva 2014/24/UE. Nesta leitura, a informação a prestar aos operadores de mercado por via consultas preliminares não deve equivaler ou superar a informação constante do referido anúncio, o que aponta, essencialmente, para os cuidados a ter pela entidade adjudicante com o nivelamento do grau e timing da informação sobre "planos de contratação" divulgada de forma antecipada por via das consultas preliminares.

Na prática, parece-nos que as duas funções da consulta preliminar são tendencialmente mais interdependentes do que estritamente autónomas. Isto significa que a obtenção de informação para o planeamento e a preparação de contratos está muitas vezes ligada com a prestação de informação às entidades consultadas sobre os planos e termos do contrato pretendido celebrar. Com efeito, esta relação dialética entre a entidade adjudicante e entidade consultada serve, na maioria das vezes, propósitos informativos de benefício mútuo.

Neste sentido, torna-se mais difícil conceber situações em que a consulta serve exclusivamente a função de planear e preparar as peças do procedimento, sem que a entidade consultada tenha pelo menos a expectativa de poder vir a participar no procedimento adjudicatório. A questão prende-se com o incentivo que esta entidade consultada, em particular quando seja um potencial operador interessado em participar no procedimento, possui na prestação de informações

67 Cf. Michael Steinicke, Brussels Commentary on EU Public Procurement Law, op. cit., p. 517.

68 Através de um anúncio de pré-informação publicado no Jornal Oficial da União Europeia. Sobre esta possibilidade, Cf. Sue Arrowsmith, The Law of Public and Utilities Procurement..., op. cit., p. 652.

69 Neste sentido, cf. Michael SteiniCKe and Peter L. Vesterdof, Brussels Commentary on EU Public Procurement Law, op. cit., p. 517: "Article 52 does not give complete freedom to publish notices, as there are conditions governing the timing and content of sucb notices. It must be assumed that the same rules apply to a contracting authority's approaches to the market prior to the publication of any notice. [...] According to article 52, there must at least be the same restrictions on giving notice under article 40 as under article 52 in relation to publishing a notice at national level with more specific information about the contract". 
quando não seja remunerada diretamente por esta, ou quando não obtenha uma outra vantagem resultante dessa prestação. Pode suceder que a remuneração, não sendo direta, possa estar "incluída" na remuneração a obter por via do futuro contrato sobre o qual a entidade consultada, que é simultaneamente um potencial operador interessado, prestou informações técnicas ou o seu parecer. Esta descrição sucinta corresponde ao fenómeno de favorecimento do candidato / concorrente-consultado, que o legislador europeu pretende evitar na formulação do regime das consultas preliminares, através do enunciado declarativo de alguns limites tendentes a prevenir situações de distorção da concorrência, e de violação dos princípios da igualdade e transparência.

De facto, da consulta não pode resultar uma situação em que a entidade consultada obtenha uma vantagem informativa relevante, seja na perspetiva do conteúdo da informação obtida, seja na perspetiva da vantagem temporal na obtenção de informação em relação aos demais potenciais operadores interessa$\operatorname{dos}^{70}$. A compreensão dos limites sobre a utilização do mecanismo da consulta preliminar ao mercado, impõe a leitura conjugada das normas dos artigos $40{ }^{\circ}$ e 41. ${ }^{\circ}$ da Diretiva 2014/24/UE. Resulta deste último preceito, sob a epígrafe "Participação prévia de candidatos ou proponentes", o seguinte:

- "Quando um candidato ou proponente, ou uma empresa associada a um candidato ou proponente, tiver apresentado um parecer à autoridade adjudicante, quer no contexto do artigo $40{ }^{\circ}$, quer não, ou tiver participado de qualquer outra forma na preparação do procedimento de contratação, a autoridade adjudicante toma as medidas adequadas para evitar qualquer distorção da concorrência em virtude dessa participação do candidato ou proponente.

Entre essas medidas inclui-se a comunicação aos restantes candidatos e proponentes das informações pertinentes trocadas no âmbito ou em resultado da participação do candidato ou proponente na preparação do procedimento de contratação, assim como a fixação de prazos adequados para a receção de propostas. O candidato ou proponente em causa só deve ser excluído do procedimento se não existirem outras formas de garantir o cumprimento do dever de observância do princípio da igualdade de tratamento.

Antes de qualquer exclusão por esses motivos, é dada aos candidatos ou proponentes a oportunidade de demonstrarem que a sua participação na preparação do procedimento de contratação não é suscetível de distorcer a concorrência. As medidas tomadas são documentadas no relatório exigido nos termos no artigo $84 .^{{ }^{\circ \prime}}$ - itálico nosso.

70 Cf., neste sentido, Sue Arrowsmith, The Law of Public and Utilities Procurement, Regulation in the EU and the UK, op. cit., p. 652; STEEn TReUmer, "Technical dialogue and the principle of equal treatment - dealing with conflicts of interest after Fabricom", Public Procurement Law Review, vol. 2, 2007, p. 116. 
Repare-se, numa primeira nota, que os limites à condução da fase préprocedimental pelas entidades adjudicantes são traçados neste preceito de forma mais abrangente, incluindo-se no leque de situações de possível favorecimento do candidato / concorrente-consultado, suscetíveis de distorcer a concorrência, aquelas que não são originadas por via da consulta preliminar, o que resulta do segmento normativo "quer no contexto normativo do artigo $40{ }^{\circ}$, quer não". A vocação de "catch all provision" 71 inerente a este segmento normativo aponta no sentido da sua natureza meramente explicativa, no sentido de tornar inequívoco aos olhos do intérprete que se pretende abranger casos em que, por razões formais na própria utilização do mecanismo - em que não se mencione explicitamente que se está a realizar uma "consulta preliminar ao mercado", ou não se utilize uma determinada plataforma oficial para o efeito, como sucede na Eslováquia ${ }^{72}$-, não deixam de dever ser respeitados os limites que previnam situações de distorções de concorrência, e de violação da transparência e igualdade.

Neste âmbito alargado de prevenção, identificam-se determinados deveres da entidade adjudicante na condução das consultas preliminares por referência ao vetor da transparência da informação trocada, para prevenção de possíveis vantagens informativas relevantes e, assim, evitar situações de distorção da concorrência por via do favorecimento de certos operadores consultados em detrimento de outros - que sejam operadores consultados ou não. Destes princípios regentes da contratação pública, irradiam deveres para a entidade adjudicante na condução destas consultas preliminares ${ }^{73}$. Num enunciado exemplificativo ${ }^{74}$ de deveres, prevê-se no artigo $41 .^{\circ}$ a comunicação das informações pertinentes trocadas no âmbito da consulta aos restantes candidatos e proponentes, assim como a fixação de prazos adequados para a receção de propostas que compensem eventuais vantagens temporais conferidas às entidades consultadas.

Na prática, o registo documental do resultado das atividades informais desenvolvidas no âmbito das consultas afigura-se um passo instrumental necessário - que sucede na maioria das vezes, em diferentes medidas consoante as circunstâncias concretas - para, precisamente, possibilitar à entidade adjudicante o cumprimento destes deveres de transparência - o que implica até a inclusão

71 Cf. Michael Steinicke and Peter L. Vesterdof, EU Public Procurement Law ..., op. cit., p. 520.

72 Cf. European Commission, Prior Market Consultations, E-Library of Public Procurement Good Practises, p. 3. Disponível em https://ec.europa.eu/regional_policy/sources/good_practices/ GP_fiche_22.pdf.

73 Sobre este aspeto, veja-se Steen Treumer, "Technical dialogue prior to submission of tenders and principle of equal treatment of tenderers", Public Procurement Law Review, vol. 3, 1999, p. 157.

74 Cf. Michael Steinicke and Peter L. Vesterdoof, EU Public Procurement Law..., op. cit., p. 530 
das medidas tomadas no relatório de contratação pública ${ }^{75}$ - tendo em vista a prevenção de situações de distorção da concorrência e tratamento desigual entre operadores ${ }^{76}$. Assim, o grau de informalidade no processamento das consultas preliminares é variável, podendo até justificar-se a formalidade do processamento e do resultado das consultas consoante as exigências de transparência que no caso concreto sejam necessárias cumprir pela entidade adjudicante.

A noção de que o artigo $41 .{ }^{\circ}$ consagra um elenco exemplificativo de deveres de transparência a cargo da entidade adjudicante resulta, a nosso ver, um pouco mais evidente da letra da versão inglesa da Diretiva, a qual neste ponto dispõe o seguinte:

- "Where a candidate or tenderer or an undertaking related to a candidate or tenderer has advised the contracting authority, whether in the context of Article 40 or not, or has otherwise been involved in the preparation of the procurement procedure, the contracting authority shall take appropriate measures to ensure that competition is not distorted by the participation of that candidate or tenderer.

Such measures shall include the communication to the other candidates and tenderers of relevant information exchanged in the context of or resulting from the involvement of the candidate or tenderer in the preparation of the procurement procedure and the fixing of adequate time limits for the receipt of tenders. The candidate or tenderer concerned shall only be excluded from the procedure where there are no other means to ensure compliance with the duty to observe the principle of equal treatment.

$[\ldots]$ The measures taken shall be documented in the individual report required by Article 84." - itálico nosso.

De outro ângulo de análise, a leitura conjugada dos artigos $40 .^{\circ}$ e $41 .^{\circ}$ da Diretiva 2014/24/UE permite traçar os limites na utilização do mecanismo da consulta preliminar ao mercado, os quais, simultaneamente, traduzem aspetos sobre os termos em que esta deve ser processada pelas entidades adjudicantes. De facto, apesar de não resultar do artigo $40 .^{\circ}$ qualquer orientação sobre a forma de processamento destas consultas ${ }^{77}$, facto é que do artigo $41 .^{\circ}$ resulta um importante aspeto de transparência na sua realização, através do dever que

75 No ordenamento jurídico português foi consagrada uma solução em que se prevê a inclusão das medidas de transparência nas peças do procedimento, cf. artigo $35 .^{\circ}-\mathrm{A}, \mathrm{n} \cdot{ }^{\circ} 4$, do Código dos Contratos Públicos. Sobre alguns problemas suscitados por esta solução, cf. Pedro Fernández SÁnchez, Direito da Contratação Pública, op. cit., pp. 532-536.

76 Em sentido convergente com esta asserção, cf. SuE ArROwSMITH, The Law of Public and Utilities Procurement, Regulation in the EU and the UK, op. cit., p. 653.

77 Cf., neste sentido, Cf. Sue Arrowsmith, The Law of Public and Utilities Procurement, Regulation in the EU and the UK, op. cit., p. 652. 
recai sobre a entidade adjudicante de igualar o grau e o timing da informação entre os operadores consultados e aqueles que não foram. Quanto ao grau, impõe-se que a informação trocada com os consultados sobre o planeamento do contrato seja comunicada aos restantes operadores não consultados. Quanto ao timing, determina-se que esta comunicação seja feita em tempo útil que lhes confira igualdade de oportunidade no acesso ao contrato planeado.

Além dos deveres de nivelamento de grau e timing na informação trocada, decorre para a entidade adjudicante uma fundamental exigência de não distorção da concorrência no seguimento destas consultas preliminares, ancorada nas raízes europeias da figura do "diálogo técnico" acima identificadas, por via da construção de peças do procedimento que não sejam "à medida" de determinado candidato/ concorrente-consultado ${ }^{78}$.

A exigência de cumprimento destes deveres pela entidade adjudicante parece-nos natural e ajustada na medida em que, em regra, é aquela a entidade responsável pela condução da fase de planeamento e preparação dos contratos que pretenda celebrar. Independentemente dos impulsos externos informais que existam por parte de operadores em determinadas situações com "iniciativas/sugestões de contratos" - impulsos pré-procedimentais estes realizados por vezes com o alcance de propostas não solicitadas ${ }^{79}-$, facto é que, em geral, a iniciativa é oficiosa, pertencendo a condução destas consultas na fase de planeamento exclusivamente às entidades adjudicantes. Esta asserção justifica-se neste contexto normativo que impõe uma acrescida responsabilização das entidades adjudicantes na utilização das consultas preliminares para evitar que delas resultem elementos que "contaminem" a efetiva concorrência entre os operadores de mercado no subsequente procedimento pré-contratual ${ }^{80}$.

78 Sobre o risco da distorção da concorrência por via das tailor-made specifications, veja-se, entre outros, Steen Treumer, "Technical dialogue and the principle of equal treatment - dealing with conflicts of interest after Fabricom", op. cit., pp.99-116.

79 Sobre a matéria das propostas não solicitadas na doutrina portuguesa, veja-se LiNO TORGAL and MARISA FONSECA, "Contributo para um Regime de Contratação de Concessões de Obras e de Serviços Públicos na sequência de propostas não solicitadas (Unsolicited Proposals), in Estudos em Homenagem ao Professor Doutor José Manuel Séroulo Correia, vol. II, Almedina, 2018 , pp. 523 e segs.

80 Neste sentido, cf. Pedro Gonçalves, Direitos dos Contratos Públicos, op. cit., 2018, p. 389 Sobre as consultas preliminares ao mercado na doutrina portuguesa, veja-se, também, Miguel Assis Raimundo, A formação dos contratos públicos..., op. cit., pp. 683-725, RaQueL Carvalho, "Consultas preliminares ao mercado no CCP", in Carla Amado Gomes, Ricardo Pedro, Tiago Serrão and Marco Caldeira (coords.), Comentários à Revisão do Código dos Contratos Públicos, AAFDL, 2018, pp. 413 e segs; Sandra TaVares MagalHães, "A consulta preliminar ao mercado", Revista dos Contratos Públicos, n. ${ }^{\circ}$ 21, 2019, pp. 83-103; Pedro Fernández SánCheZ, Direito da Contratação Pública, op. cit., pp. 527-541; José Duarte CoImbra, "Planeamento da Contratação e Consultas Preliminares ao Mercado", in Maria João Estorninho and Ana Gouveia Martins (coords.), Actas da Conferência A Revisão do Código dos Contratos Públicos, ICJP-CIDP, 2016, pp. 120-142. 
Além do referido, proíbe-se a exclusão automática do concorrente que foi entidade consultada em obediência ao princípio da proporcionalidade, e na linha da jurisprudência do Acórdão Fabricom ${ }^{81}$. Neste sentido, atribui-se ao candidato ou concorrente suspeito de ter sido beneficiado o ónus de demonstrar que não o foi, conforme resulta do disposto no artigo $41 .^{\circ}$ da Diretiva. No entanto, não esqueçamos que a arguição de uma situação de eventual distorção da concorrência e tratamento desigual por prévia participação na consulta preliminar deve, em nosso entender, originar, em primeira linba, um ónus sobre a entidade adjudicante no sentido de demonstrar que deu cumprimento aos deveres de comunicação e de fixação de prazo acima referidos, entre outros que a legislação nacional dos Estados Membros preveja, e que, consequentemente, o candidato ou concorrente admitido não foi favorecido ${ }^{82}$. Em sentido complementar, se existir de facto uma situação de favorecimento oculta que não fosse exigível à entidade adjudicante controlar através dos seus deveres de transparência, deve ser dada a palavra ao concorrente visado para demonstrar que não foi favorecido com a consulta preliminar. É neste sentido, atendendo à letra e teleologia do preceito, que nos parece que o terceiro parágrafo do artigo $41 .^{\circ}$ da Diretiva deve ser interpretado.

Admitir-se, a partir deste preceito e da jurisprudência europeia, que recai sobre o candidato/concorrente-consultado o ónus de demonstrar que não foi favorecido pela entidade adjudicante que o consultou seria "minar" qualquer possibilidade de efeito útil deste mecanismo, atendendo ao risco que representaria para os eventuais interessados participarem numa qualquer consulta preliminar: nunca saberiam se, mais tarde no procedimento, por via de uma impugnação de um concorrente com acesso ao registo das consultas, não teriam de provar factos negativos relativos ao seu não favorecimento pela entidade adjudicante. De qualquer modo, o que nos parece encontrar-se previsto neste preceito reconduz-se, apenas, a um dever de audiência prévia do candidato/ concorrente-consultado, o que não deve, ainda assim, fazer precludir a verificação pela entidade adjudicante de que cumpriu os deveres de transparência nas informações trocadas com todas as entidades consultadas.

Por último, e ainda quanto à forma como esta consulta preliminar deve ser processada pelas entidades adjudicantes, já vimos que a norma do artigo $40 .^{\circ}$

81 Processos C-21/03 e C-34/03. Veja-se, sobre a condução do diálogo técnico com o mercado em conformidade com o princípio da igualdade de tratamento, Steen Treumer, "Technical dialogue and the principle of equal treatment...", op. cit., pp. 99-115; Sue Arrowsmith, "The Problem of Discussions with Tenderers under the EC Procurement Directives", Public Procurement Law Review, vol. 7, 1998, p. 65. No contexto do sistema dinamarquês, veja-se sobre esta matéria Steen Treumer, "Technical dialogue prior to submission of tenders...", op. cit., pp. 147-160.

82 Em sentido idêntico, veja-se STEEN TREUMER, "Technical dialogue prior to submission of tenders...", op. cit., p. 148; STEEN TReumer, "Technical dialogue and the principle of equal treatment...", op. cit, pp. 115-116. 
possui uma redação aberta com um enunciado exemplificativo de muito pouca densidade, indicando apenas que a consulta pode ser realizada através da obtenção ou aceitação de pareceres de peritos ou autoridades independentes ou de participantes no mercado que possam ser utilizados no planeamento e na condução do procedimento de contratação.

Sem prejuízo dos deveres que incumbem às entidades adjudicantes, acima referidos, confere-se-lhes ampla margem de discricionariedade quanto aos termos concretos em que as consultas devem ser processadas, na linha do carácter facultativo da utilização deste instrumento, constando de algumas orientações de soft law a indicação de boas práticas no processamento deste mecanismo. Quanto à forma, além da possibilidade já referida de a consulta preliminar ser anunciada por via de um anúncio de pré-informação ${ }^{83}$, pode a consulta ser processada por vias informais através do contacto seletivo com determinadas entidades. As consultas podem consistir em iniciativas feitas através de contactos telefónicos, reuniões, ou ainda por contactos via plataformas eletrónicas.

Recomenda-se, sempre que ajustado, a utilização nas consultas de questionários idênticos a serem preenchidos diretamente pelas entidades consultadas, ou a serem utilizados pelas entidades adjudicantes em contactos telefónicos conduzidos por entidades terceiras, tendo em vista garantir a maior objetividade e igualdade no tipo de informação solicitada a diferentes operadores ${ }^{84}$. Como exemplo de boas práticas na condução das consultas no seio dos Estados Membros da União Europeia aponta-se o caso da plataforma eletrónica utilizada por uma entidade adjudicante na Eslováquia, através da qual as consultas preliminares são conduzidas no sentido de garantir a maior transparência ${ }^{85}$.

No que respeita ao conteúdo da consulta preliminar ao mercado, recomenda-se que as iniciativas sejam devidamente documentadas e comunicadas por escrito relativamente a cada procedimento de contratação, de modo a assegurar a transparência da atividade ${ }^{86}$. Por seu turno, e na linha do referido sobre a necessidade de o planeamento ser atempado, indica-se que as consultas preliminares devem ser executadas com antecedência em relação à data estimada pelas entidades adjudicantes para a publicação do anúncio de concurso ${ }^{87}$. Neste ponto, a determinação do momento temporal de realização das consultas deve ser escolhido tendo em conta vários fatores, como sejam o tempo que é necessário despender com as demais atividades de planeamento (v.g. preparação das peças do procedimento), bem como a necessidade de o adequar, em face

83 Cf., neste sentido, cf. Sue Arrowsmith, The Law of Public and Utilities Procurement..., op. cit., p. 652.

84 Cf. European Commission, Prior Market Consultations, op. cit.

85 Cf. ibid., p. 3.

86 Cf. european commission, Public Procurement Guidance for Practitioners, op. cit., p.23.

87 Cf. ibid., p. 25 
do seu grau de detalhe, da complexidade - e acrescentaríamos, do valor - do (s) contrato (s) planeado (s).

\section{NOTAS CONCLUSIVAS}

No contexto de crescente perceção pelos órgãos institucionais europeus da relevância jurídico-prática decisiva que a diligente condução da fase planeamento da contratação pública possui, verifica-se que a abordagem escolhida pela Comissão Europeia para potenciar o uso do planeamento é a de, essencialmente, sensibilizar as entidades adjudicantes dos Estados Membros para a sua relevância, bem como para alguns aspetos de forma e conteúdo, por via de instrumentos de utilização facultativa e de orientações de soft law.

Naturalmente, esta abordagem orientadora não vincula - nem de resto assume esse propósito - as entidades adjudicantes a efetivamente planearem as suas aquisições de forma racional e transparente. Porém, apesar de a sensibilização ser absolutamente necessária, não podemos deixar de olhar com alguma apreensão para o escasso quadro regulatório europeu neste âmbito, em particular quando consideramos os dados do Tribunal de Contas Europeu sobre os erros mais graves detetados na fase de planeamento e preparação da contratação pública, e a noção empírica de que o planeamento é, muitas vezes, negligenciado pelas entidades adjudicantes com prejuízo direto do desígnio clássico do direito europeu de estímulo à igualdade de oportunidades de acesso ao mercado dos contratos públicos, assim como dos objetivos mais recentes de sustentabilidade, inovação e eficiência.

Neste enquadramento, questionamo-nos sobre a adequação da abordagem europeia ao tema do planeamento, em particular quando verificamos que as normas aplicáveis diretamente à fase de planeamento - os anúncios de préinformação e as consultas preliminares ao mercado - são ainda desprovidas da densidade e do conteúdo vinculativo que permitam garantir, pelo menos, que as entidades conduzam efetivamente alguma atividade de planeamento da contratação e utilizem, para o efeito, aqueles instrumentos com ainda maior segurança jurídica. Não obstante o referido, não se pode ignorar a significativa e salutar evolução de regime em 2014 no que respeita à expressa legitimação da utilização das consultas preliminares pelas entidades adjudicantes, num ponto de equilíbrio difícil de alcançar através da necessária amplitude na discricionariedade do seu exercício "temperada" pela identificação de claros limites a salvaguardar no seu processamento. Subjaz às normas europeias um sentido global de sensibilização das entidades adjudicantes para a utilização responsável e sensata deste instrumento preliminar, tendo em vista acautelar a igualdade de tratamento entre operadores consultados e não consultados no âmbito do procedimento adjudicatório subsequente.

Estamos em crer que este tema merecerá novas abordagens regulamentadoras em futuras reformas do direito europeu da contratação pública, no sentido 
de garantir que determinados standards mínimos de planeamento de vocação mais abrangente sejam efetivamente cumpridos pelas entidades adjudicantes - desde logo, a sua realização em determinados momentos temporais, e a sua publicitação em determinadas circunstâncias. A eventual harmonização legislativa neste âmbito deve, acima de tudo, potenciar, por via do planeamento, a maior qualidade do "convite a contratar" formulado pelas entidades adjudicantes dos Estados-Membros e, como consequência, o maior acesso dos operadores económicos aos mercados.

Nos termos acima explicitados, não pensamos que uma abordagem regulamentadora neste domínio se traduzisse numa atuação à margem das competências da União Europeia, e muito menos representasse uma "inflexão de sentido" quanto à nociva prática de crescente complexificação do quadro normativo europeu das Diretivas, assente na aparente desconfiança do legislador europeu na capacidade e vontade das entidades adjudicantes dos Estados Membros de cumprirem os objetivos europeus. Por isso, será preciso, em nossa opinião, alcançar nesta matéria uma proporcional regulamentação de aspetos mínimos estruturantes da atividade de planeamento, em sintonia com as melhores práticas e os exemplos de outros sistemas jurídicos.

\section{BIBLIOGRAFIA}

\section{DOUTRINA}

Albano, Gian Luigi. Competition in Public Procurement Markets, Paper for Working Party on Competition and Regulation OECD, 2017.

Arrowsmith, Sue. "Public Procurement Regulation: An introduction". In The EU Asia Inter University Networkfor Teaching and Research in Public Procurement Regulation, 2010.

Arrowsmith, Sue. "The Problem of Discussions with Tenderers under the EC Procurement Directives". Public Procurement Law Review, vol. 7, 1998.

Arrowsmith, Sue. "The purpose of the EU Procurement Directives: Ends, Means and the Implications for National Regulatory Space for Commercial and Horizontal Policies". In Cambridge Yearbook of European Legal Studies, vol. 14, 2012.

Arrowsmith, Sue. The Law of Public and Utilities Procurement, Regulation in the EU and the UK, vol. I, 3. ${ }^{a}$ ed. UK: Sweet \& Maxwell, 2014.

Arrowsmith, Sue, Ruth Bayley, Anna Gorczynska, Joshua Idoku, Steve Kay, Jorge Faria Lopes, Carlos Sebastian Barreto Cifuentes, Geo Quinot, Ke Ren, AshrafUl-Bari Nobel, Astghik Solomanyan, Izabella Sobieraj, Gábor Soós and Alex ThuRSTON. "Procuring Infrastructure for International Sporting Events: Mapping the Field for IPACs and Beyond". Public Procurement Law Review, vol. 28, n. ${ }^{\circ}$ 6, 2019. 
Burgi, Martin. "Specifications". In Martin Trybus, Roberto Caranta and Gunilla Edelstam (eds.), EU Public Contract Law. Public Procurement and Beyond. Bruxelas: Bruylant, 2013.

Carvalho, Raquel. "Consultas preliminares ao mercado no CCP". In Carla Amado Gomes, Ricardo Pedro, Tiago Serrão and Marco Caldeira (coords.), Comentários à Revisão do Código dos Contratos Públicos. AAFDL, 2018.

Coimbra, José Duarte. "Planeamento da Contratação e Consultas Preliminares ao Mercado". In Maria João Estorninho and Ana Gouveia Martins (coords.), Actas da Conferência A Revisão do Código dos Contratos Públicos. ICJP-CIDP, 2016.

Comba, Mario E. "Variations in the scope of the new EU public procurement Directives of 2014: Efficiency in public spending and a major role of the approximation of laws". In François Lichère, Roberto Caranta and Steen Treumer (eds.), Modernizing Public Procurement: The New Directive. Denmark: DJof Publishing, 2014.

Coutinho, Juliana Ferraz. "A decisão de contratar e as suas circunstâncias". Revista dos Contratos Públicos, n. ${ }^{\circ} 23,2020$.

Davidoff, Paul and Thomas A. Reiner. "A Choice of Theory of Planning". In Andreas Faludi (ed.), A Reader in Planning Theory. Oxford: Pergamon Press, 1973.

Gonçalves, Pedro. Direitos dos Contratos Públicos, 2. ${ }^{a}$ ed. Almedina, 2018.

Hawkins, Timothy G. and William A. Muir. "An Exploration of Knowledge-Based Factors Affecting Procurement Compliance". Journal of Public Procurement, vol. 14, n. ${ }^{\circ} 1,2014$.

Kelman, Steven. Procurement and Public Management, The Fear of Discretion and the Quality of Government Procurement., Washington: AEI Press, 1990.

Kunzlik, Peter. "Neoliberalism and the European Public Procurement Regime". In Cambridge Yearbook of European Legal Studies, vol. 15. Cambridge: Cambridge University Press, 2013.

Magalhães, Sandra Tavares. "A consulta preliminar ao mercado". Revista dos Contratos Públicos, n. ${ }^{\circ} 21,2019$.

Pegnato, Joseph. "Assessing Federal Procuring Reform: Has the Procurement Pendulum Stopped Swinging?". In Khi V. Thai (ed). International Handbook of Public Procurement. New York: Routledge, 2009.

Poulsen, Sune Troels, Peter Stig Jakobsen and Simon Evers Kalsmose-Hjelmborg.

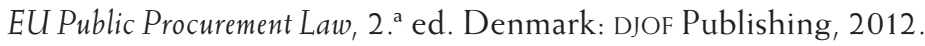


Raimundo, Miguel Assis. A formação dos contratos públicos - Uma concorrência ajustada ao interesse público. Lisboa: AAFDL, 2013.

SÁnchez, Pedro Fernández. Direito da Contratação Pública, vol. I. Lisboa: AafdL, 2020.

Spagnolo, Giancarlo and Christopher Yukins. "Lots - The Economics and Legal Challenges of Centralized Procurement. Colloquium". In: Gustavo Piga and Tunde Tatrai (eds.), Public Procurement Policy. New York: Routledge, 2016.

Steinicke, Michael and Peter L. Vesterdof. EU Public Procurement Law - Brussels Commentary. Bruxelas: Nomos, 2018.

Telles, Pedro and Luke R. A. Butler. "Public Procurement Award Procedures in Directive 2014/24/EU". In François Lichère, Roberto Caranta, \& Steen Treumer, (eds.), Modernising Public Procurement: The New Directive. Denmark: DJof Publishing, 2014.

Torgal Lino and Marisa Fonseca. "Contributo para um Regime de Contratação de Concessões de Obras e de Serviços Públicos na sequência de propostas não solicitadas (Unsolicited Proposals). In Estudos em Homenagem ao Professor Doutor José Manuel Sérvulo Correia, vol. II. Almedina, 2018.

Trepte, Peter. Regulating Procurement: Understanding the Ends and Means of Public Procurement Regulation. Oxford: Oxford University Press, 2004.

Treumer, Steen. "Evolution of the EU Public Procurement Regime: The New Public Procurement Directive". In François Lichère, Roberto Caranta and Steen Treumer (eds.), Modernizing Public Procurement: The New Directive, Denmark: DJOF Publishing, 2014.

Treumer, Steen. "Technical dialogue and the principle of equal treatment - dealing with conflicts of interest after Fabricom". Public Procurement Law Review, vol. 2, 2007.

Treumer, SteEn. "Technical dialogue prior to submission of tenders and principle of equal treatment of tenderers". Public Procurement Law Review, vol 3, 1999.

Trybus, Martin, Roberto Caranta and Gunilla Edelstam. "Introduction". In Martin Trybus, Roberto Caranta and Gunilla Edelstam (eds.), EU Public Contract Law. Public Procurement and Beyond. Bruxelas: Bruylant, 2013.

Voda, Oana Pantilimon and Caroliene Jobse. "Rules and Boundaries Surrounding Preliminary Market Consultations in Innovation Procurement: Understanding and Addressing the Legal Risks". European Procurement \& Public Private Partnerships Law Review, vol. 11, n. ${ }^{\circ}$ 3, 2016.

SOFt LAW E RELATÓRIOS

European Commission, Buying Green! A Handbook on green public procurement, 3. a ed., 2016. 
European Commission, Commission Notice Guidance on Innovation Procurement, 2018.

European Commission, Prior Market Consultations, E-Library of Public Procurement Good Practices. Disponível em https://ec.europa.eu/regional_policy/sources/ good_practices/GP_fiche_22.pdf.

European Commission, Public Procurement Guidance for Practitioners, February 2018. Disponível em: https://ec.europa.eu/regional_policy/sources/docgener/guides/ public_procurement/2018/guidance_public_procurement_2018_pt.pdf [consultado em 27/03/19].

European Commission, Publish Annual Procurement Plans, E-Library on Public Procurement Good Practices. Disponível em https://ec.europa.eu/regional_policy/sources/ good_practices/GP_fiche_12.pdf.

European Commission, Single Market Scoreboard, 2018. Disponível em https://ec.europa. eu/internal_market/scoreboard/_docs/2019/performance_per_policy_area/public_procurement_en.pdf.

OECD/SIGma, Market Analysis, Preliminary Market Consultations, and Prior Involvement of Candidates/Tenderers. OECD/SIGMA 2016.

Tribunal de Contas Europeu, Relatório Especial, "Devem intensificar-se os esforços para resolver os problemas relacionados com a contratação pública nas despesas da Coesão da União Europeia", Anexo III, União Europeia, 2015.

World Bank, Uganda Country Procurement Assessment Report (CPAR), vol. II, Main Findings and Recommendations, 2004. 